\title{
Quality Assurance Implementation Practices in Selected Malaysian Public Universities
}

\author{
Baboucarr Njie ${ }^{a}$, Soaib Asimiran ${ }^{b}$, Ramli Basri $^{\text {b }}$, Suhaida Abdul Kadir \\ ${ }^{a}$ Regional Maritime University, Nungua, Accra, Ghana \\ ${ }^{\mathrm{b}}$ Universiti Putra Malaysia, Serdang, Malaysia \\ Corresponding e-mail: $\underline{\text { soaib@upm.edu.my }}$
}

\begin{abstract}
The quest to improve and compete globally has prompted universities around the world to subscribe to quality assurance practices and the Malaysian public universities are no exception. This study was conducted with the aim of exploring the quality assurance practices in Malaysian public universities and the challenges faced by those entrusted to oversee the implementation processes. Utilizing qualitative approach, we examined in-depth the experiences and views of fourteen informants through interviews, who were entrusted with managing quality assurance practices in the selected universities. Four major themes emerged comprising commitment to addressing quality assurance, quality management system, understanding of quality assurance implementation, and challenge to nurture quality culture. Interestingly, the universities have well documented policies on quality assurance implementation and proper structures to oversee the quality assurance practices adhering to government policies and aspirations. However, there were differences in the interpretation and understanding of quality assurance practices among the two major groups of informants, the academics and the full time career administrators. Despite the efforts also, the universities faced with various challenges to nurture quality culture among the staff and much more are still needed if Malaysian universities are to be regarded as providing quality services within the framework of quality assurance practices.
\end{abstract}

Keywords: Quality Assurance, Malaysian Public Universities, Quality Culture, Quality Assurance Implementation

\section{INTRODUCTION}

Universities and the quality of their programs play a crucial role in the transformation of students to meet the socioeconomic needs of societies as well as fulfilling national aspiration. Universities serve as the guiding torches in national development through the production of the critical human resources needed to steer a country in the desired direction for development. Universities are now serve many purposes, more than just cultural and educational institutions because they are the symbols of pride for comparison among nations (Salmi, 2009).

Quality assurance practices are eminent in most universities agenda to achieve a better ranking (Stamatelos, 2010). University ranking systems and standard quality assurance frameworks such as the ISO 9000 Series and other quality assurance initiatives have made the focus of quality assurance as a crucial factor in universities' attempt to gain recognition.

In this regard, the quest to continuously improve and compete globally has prompted universities around the world to subscribe to quality assurance practices and the Malaysian public universities are no exception. As a respond, this paper aims to discuss the findings of a study conducted in relation to quality assurance practices in Malaysian public universities.

Quality Assurance practices have been identified as mechanisms to attain recognition as quality universities. Broadly speaking, quality assurance refers to the policies and processes directed to ensuring the maintenance and enhancement of quality (Lim, 2001). Quality assurance is deeply rooted in systematic practices that are dictated by the regulatory bodies as the benchmarks upon which universities strive to achieve the required standards. Quality assurance is a 
theme with an unchallenged position in the discussions around higher education since the 1980s and 1990s (Westerheijdena et al, 2007). Westerheijdena et al argued that quality assurance schemes were introduced as national policy instruments in France (1984), the UK (1985), and the Netherlands (1985).

Universities in Asia, as in other parts of the world are facing mounting pressures to perform better in order to be able to compete other reputable universities and to attain world-class status (Mok \& Wei 2008; Mok, 2010). Following that, the 1990s saw drastic restructuring of higher education across the globe and through cultural diffusion and institutional isomorphism (Lee, 2004) many countries, including Malaysia, instituted reforms to effect the changes in line with the changing global landscape for higher education (Sirat \& Kaur, 2010). In Malaysia, the amendment of the Universities and University Colleges' act, 1996 resulted with the corporatization of all public Universities (Sirat \& Kaur, 2010). This marked the turning point of quality assurance issues in all universities in Malaysia. The uniform appearance will assist the reader to read paper of the proceedings. It is therefore suggested to authors to use the example of this file to construct their papers. This particular example uses an American letter format with $25 \mathrm{~mm}$ margins left, right, top and bottom.

In Malaysia, the Malaysian Qualification Agency (MQA) established in 2007 is specifically tasked with quality monitoring of higher education in the country. Above all, higher education in Malaysia is expected to be at par with that being offered elsewhere (Ministry of Higher Education, 2007).

Institutions of higher education in Asia, as in other parts of the world, have experienced intense pressure to perform well in order to be in a better position to compete on a global level and attain world-class status (Mok \& Wei 2008; Mok, 2010). Quality Assurance practices have been one important tool used to attain such status. The tension between quality as a ritual and quality as it is seen by its stakeholders (Harvey, 2006) shows its complicated relationship in terms of its understanding, perspectives, implementation, involvement and the challenges that continue to confront it. Several studies were conducted in Malaysia on quality assurance. Konting et al. (2009) assessed the graduating students' satisfaction; Lim (2010) focused on the experiences and challenges faced by private tertiary education providers in Malaysia and Singapore; Rosdi (1999) studied the quality improvement process for teaching through ISO9000 while Dzafir (2009) focused on the implementation of quality assurance. In addition, Tew (2013) studied final year students' satisfaction in a branch campus university of an international university. These studies examined quality assurance themes in Malaysia but none concentrated, in substantial depth, on the human element; that comprised the practical experience between what is set out to be achieved in the practices and the reality of implementation in terms of its understanding, appreciation and acceptance and all those challenges.

The objective of the study was to explore the quality assurance practices in selected Malaysian public universities and the challenges faced by those entrusted to oversee the implementation processes.

Specifically, the objectives are: 1) To examine how quality assurance implementation are conducted in Malaysian public universities; 2) To explore the understanding of those entrusted to oversee the process on quality assurance practices; 3 ) To explore the extent of involvement of the internal stakeholders in the implementation of quality assurance processes; and 4) To examine the challenges faced during the implementation of quality assurance processes.

\section{METHODS}

This study aims at looking into the quality assurance practices, their implementation and the challenges faced. The emphasis is on the practices, the processes and the bonds or relationships as well as the meaning of all these. This nature of inquiry would benefit from the research paradigm offered by the qualitative methodology. Utilizing qualitative approach, we examined in-depth the experiences and views of fourteen informants through interviews, who were entrusted with managing quality assurance practices in the selected universities.

We utilized interviews and document analysis as the sources of data collection. While interviews were the primary source of data collection, the document analysis worked to verify and authenticate interviews from the informants. This has helped in both enabling receipt of information from various sources thus fulfilling the triangulation as well as enabling the comparison and analysis of data through different means thus the testing of veracity of the information. The reliability of the research activity could also be confidently argued with the sources of data collection.

Four major themes emerged comprising commitment to addressing quality assurance, quality management system, understanding of quality assurance implementation, and challenge to nurture quality culture. Interestingly, the universities have well documented policies on quality assurance implementation and proper structures, backed by material support and units specifically tasked to oversee that the quality assurance practices adhering 
to government policies and aspirations. However, there were differences in the interpretation and understanding of quality assurance practices among the two major groups of informants, the academics and the full time career administrators.

\section{RESULTS AND DISCUSSION}

\section{What is the nature of implementation of quality assurance processes?}

The strong commitment to addressing quality for the actualization of educational goals of the universities was obvious from the interviews and document analysis. The evidence to this apparent state of being is strengthened by the presence of established quality assurance structures in the selected universities in this study. The structures were well organized and all inclusive implementation processes and the presence of a generic quality assurance framework. A principal message that vividly clears is the commitment of the Malaysian government and the relevant authorities to the improvement and enhancement of quality. This is proven not only in the policy documents on quality, but also the resources committed to it, the setting up of the MQA, an autonomous quality assurance agency and its membership to various regional quality assurance bodies.

Explicitly the commitment to addressing quality from top to down is translated on the ground as substantiated by the following three sub-themes:

1. Quality Assurance Structures;

2. Well organized and all inclusive implementation process in place; and

3. Presence of generic quality assurance framework.

The implementation processes were found to be coherently laid with clear lines of communication and responsibilities of what each category of staff is supposed to do. This was found in quality assurance forms of the universities which spelt out clear lines of responsibilities by specifically mentioning what each category of staff is accountable to.

\section{How are the quality assurance measures understood by internal stakeholders?}

Differences in scope of understanding quality assurance among the two categories of staff interviewed as well as within them were a key finding in this research. To the quality assurance officials, who are practically the custodians of quality assurance policies and its implementation protocol, quality assurance systems are packages of change that endure normal routines of lack of understanding and resistance at the initial phases but overtime get understood and accepted. However to the majority of academic staff interviewed in this study quality assurance is not merely a change package that can be applied to a complex phenomenon, as education, without the much needed nurturing and adaptation. The absence of such nurturing and the inputs of the key stakeholders obscure its reason of being and the way it is identified with. Two dimensions of how the informants understand and interpret quality assurance practices were Quality for Improvement versus Quality for Accountability and Intra versus inter University Quality Management fulfilment.

Quality managers are of the view they are addressing quality while the majority of academic staff agree that attempts are being made but with either the wrong strategies or insufficient efforts. Quality managers were insistent that the quality systems they use have contributed manifestly in improvements of various units and sections in the university and gave specific instances to substantiate their position. However, the academic staffs while acknowledging that quality assurance system have effected changes cautioned that the nature and circumstances of the change need to be put in context. To them as academicians, improvement should be looked beyond window dressing to one that leads to impact in the overall design and purpose of the university system which they consider somewhat wanting in their universities.

\section{To what extent internal stakeholders involve in the implementation of quality assurance processes?}

The top-down nature of its arrangement also implies a bureaucratic imposition that begs for compliance. Based on the desires of top management, quality assurance regulations, although appear voluntary on paper, are thought of as being compulsory as implied in the way they are pegged to the individual staff Key Performance Indicators (KPIs). Application of quality assurance requirements merely as a means of fulfilling quality assurance requirements from the top resonated markedly in the responses of most of the academic staff from those universities.

In practice, the universities have a top-down quality assurance framework with the major policies and implementation mechanisms dictated from the 
top management. When asked why the top-down nature of quality assurance, the administrators responded by indicating that it was meant to get staff to accept it. The top down nature of quality makes it difficult for staff to resist.

As a result of the nature of quality assurance systems which is handed down from the top, staffs regarded their involvement level in the implementation of quality assurance systems reasonably high. From the interviews, they also vividly indicated that they literally understood the system and what was being asked of them. However the nature of the system, according to some of them, does not seem to be open to the type of debate that could result in changes to the system and hence to avoid unnecessarily getting into the bad books of the system or being seen to incapacitate the system, they would just act in accordance with what the regulations dictate.

\section{What are the challenges confronted in the implementation of Quality Assurance Practices?}

The cause and effect rationalization of challenges of quality assurance implementation explain the responses given by the two categories of informants. While it was not a clear cut matter of one category of staff taking a particular position, the academic staff portrayed the challenges of quality assurance as causal emanating mainly as a result of the package of quality even if other factors also affect its implementation. On the other hand, the administrative staff and quality assurance managers describe the challenges from an effect perspective attributing them more as routine issues that would usually originate from planned change like quality assurance.

To most academic staff, problems of finetuning quality assurance systems and their policies for acceptance and ownership have been the misery of its proper implementation. Hence, to them the lack of quality culture stems more from the nature of its imposition as a foreign brand which is seen to be dictated and "a must follow". To them, unpacking the quality assurance packages and engaging the staff to add flare and contextual relevance could have added more impetus to its efficiency.

For administrative staff and quality assurance managers and a few of the academic staff, the lack of quality culture was a normal and comprehensible situation of planned change with its cycles of concerns and of the inherent nature of humans to react to situations before making up their mind. In this case, since quality assurance pushes staff away from their comfort zones, a natural reaction which is resistance to change comes about. However, overtime, as they do the same thing continuously and with realization that the practices are yielding positive impacts both for the individuals and the system; it jells as a culture and will be accepted and nurtured.

Several informants were a bit more reconciliatory of quality assurance challenges as effects of the change initiative that would usually be met with some form of reaction and resistance. They pinned the challenges more as consequences of implementation of a change initiative which would be met with resistance because most of its demands may not be convenient to staff at the initial stages.

The informants lament the lack of quality culture as a general challenge that stem from staffs' resistance to change especially if that change pushes them from their "comfort zone". While they all lamented that there were clear signs of reluctance or a nonchalant attitude by staff in the implementation which they indicated is a hindrance to building quality culture, they were positive that the continuous exposure of staff to quality matters will change attitudes over time. As a result of this view, they were more optimistic that in the fullness of time, the quest for all staff to converge at a point of embracing the culture of quality will come to bear especially in view of the numerous efforts being directed at staff training and orientation on the matter.

Strong commitment to address quality resonated resoundingly from the interviews and documents on quality assurance implementation in the universities. The commitment cascaded from the top at the university level and its line authorities and trickled down to the universities' staff. Authorities in all these tiers are reported to show a great deal of interest in quality assurance development and enhancement for the respective universities. Such dedication is reported to have translated in the amount of time, energy and resources intended for quality assurance.

At the broader level, Malaysia's vision 2020 and its National Higher Education Strategic Plan Beyond 2020 emphasizes on excellence in education which is laid down to be pursued through continual improvement initiatives and benchmarking. Therefore, the current higher education policy has a lot of objectives contingent upon the success of quality assurance implementation. It is not surprising that the commitment to quality assurance is realized across the tiers of universities' management through quality documents and pronouncements.

However, differences in the manner of understanding the quality assurance purposes 
especially in view of the methods being applied emerged in this study. As custodians of quality assurance systems who are also responsible for its implementation, the administrators mainly took the constraints as normal issues that are expected to emanate from any change drive. On the other hand, the academic counterparts differed in their views as they practically described their roles as that of followers that are told what to do in order to improve ironically in the fields of specialization.

It is accepted that the quality assurance initiatives are conducted to achieve several objectives and two of them are the improvement and accountability purposes. All informants agreed that improvement and accountability are clearly among the objectives to be achieved. The obstacle was on the understanding on what activities are to be done and the determination of priorities. While the administrative staffs mainly argue on the principality of improvement as the lead in their initiatives, the majority of the academic staff looked at these actions more as outward aesthetics that are meant to paint a picture for improvement. In a way, they viewed them as hypothetical.

Above all, the commitment to quality improvement among the universities in Malaysia is obvious. This becomes more eminent during the 1990s both as a remedy to the challenges of the times then and later as a strategic vision for economic enhancement and its quest for a regional hub in education. Sohail et al (2003) relate that the Asian crisis in 1997 conditioned the countries in the region to resort to training their students domestically to save cost and at the same time develop the local universities.

The challenges of quality assurance implementation were eminent. These include: the perceptions of the quality assurance packages as foreign, lack of nurturing the packages to suit local environment and cultural settings, the top-down nature of quality policies, lack of quality culture and more pressing was the staff resistance to change. A lot has been written on the issue of institutional cultures, and more so the culture of quality among educational establishments (Trowler, 1998). Kleijnen et al (2009) investigated the perceptions of staff members about organizational culture and revealed that both a flexibility-oriented and control-oriented were experienced in practice and that staff members generally preferred a flexibility-oriented culture to the control-oriented culture.

\section{CONCLUSIONS}

Quality assurance implementation stimulates change from the familiar way of doing things to new ways of thinking and doing things, to the system perceives to be a better alternative which would bring about positive change. Above all, it is envisaged a quality culture would emerged as a new way of doing things. To embark from the usual ways of doing things to a new system requires a lot of orientation and courage, attitude change and possibly a new culture. The commitment to improve the quality at the selected universities is strong and this was match with an equal policies and actions in the selected public universities. Despite the initiatives, challenges in nurturing quality culture remain an issue to be tackled especially in the next five to ten years. Nevertheless, it is reiterated here that public universities in Malaysia are serious in quality assurance implementation.

\section{REFERENCES}

Hairuddin Mohd Ali \& Mohammed Borhandden Musah. (2012). Investigation of Malaysian higher education quality culture and workforce performance. Quality Assurance in Education, vol. 20 (3), pp. 289-309.

Harvey, L. (2006). Impact of Quality Assurance: Overview of a discussion between representatives of external quality assurance agencies. Quality in Higher Education, 12(3), 287-290.

Kleijnen, J., Dolmans, D., Muijtjens, A., Willems, J. and Van Hout, H. (2009). Organisational values in higher education: Perceptions and preferences of staff. Quality in Higher Education, 15(3), 233-249.

Lee, M. N. (2000). The politics of educational change in Malaysia: National context and global influences. Educational change and development in the AsiaPacific region: Challenges for the future, 107-131.

Lim, D. (2001). Quality Assurance in Higher Education: A Study of Developing Countries. England: Ashgate Publishing Ltd.

Ministry of Higher Education Malaysia. (2006). Report by the Committee to Study, Review and make Recommendations concerning the Development and Direction of Higher Education in Malaysia. Shah Alam: University Publication Centre (UPENA).

Mohamad Dzafir Mustafa (2009). Pelaksanaan Jaminan Kualiti Program Sarjana Muda di Universiti Awam. Unpublished Master thesis, Universiti Putra Malaysia.

Mok, K. H. \& Wei, I. P. (2008). Contested concepts, similar practices: The quest for the global university. Higher Education Policy. 21(4): 429-438.

Newton, J. (2002). Barriers to effective quality management and leadership: Case study of two academic departments. Higher Education, 44(2), 185-212. 
Rosdi Wah. (1999). Pelaksanaan Jaminan Kualiti di Universiti Putra Malaysia. Unpublished Master project paper, Universiti Putra Malaysia.

Salmi, J. (2009). The challenge of establishing world class universities: World Bank Publications.

Sirat, M. \& Kaur, S. (2010).Changing state-university relations: the experiences of Japan and lessons for Malaysia. Comparative Education, 46(2), 189-205.

Sohail, M., Rajadurai, J. \& Rahman, N. (2003). Managing Quality in Higher Education: A Malaysia case study. International Journal of Educational Management, 17(4), 141-146.

Stamatelos, A. (2010). Experience gained from the application of basic quality assurance procedures in a Greek university engineering department. European Journal of Engineering Education, 35(3), 259-270.

Tew Peng Kooi. (2013). Tahap Kepuasan Pelajar Terhadap Kualiti Perkhidmatan di University Nottingham Kampus Malaysia. Unpublished Master project paper, Universiti Putra Malaysia.

Trowler, P. R. (1998). Academics Responding to Change. New Higher Education Frameworks and Academic Cultures: ERIC.

Westerheijden, D. F., Hulpiau, V. \& Waeytens, K. (2007). From design and implementation to impact of quality assurance: An overview of some studies into what impacts improvement. Tertiary Education and Management, 13(4), 295-312. 